\title{
Flexible, Dopant Free a-Si:H Solar Cell
}

\author{
Erenn Ore ${ }^{1}$, Gehan Amaratunga ${ }^{1}$ \\ ${ }^{1}$ Department Of Engineering, University Of Cambridge, Cambridge, United Kingdom.
}

\begin{abstract}
Dopant free thin film solar cells with the common structure of $\mathrm{ZnO}: \mathrm{Al} / \mathrm{MoO}_{x} / \mathrm{a}-\mathrm{Si}: \mathrm{H} / \mathrm{LiF} / \mathrm{Al}$ are fabricated directly on flexible, transparent substrates. All the layers, except the $a$-Si: $H$ layer, are deposited by simple, low temperature physical vapour deposition methods. An open circuit voltage of $0.764 \mathrm{~V}$ and a short circuit current density of $11.31 \mathrm{~mA} /$ $\mathrm{cm}^{2}$ are measured under AM1.5 irradiance. The proof of concept for flexible, dopant free $a-S i$ : $H$ solar cell demonstrated here is a step forward towards processing cost-effective, flexible and lightweight thin film solar cells.
\end{abstract}

Index Terms - amorphous silicon, dopant free, flexible, solar cell.

\section{INTRODUCTION}

A typical inorganic thin film solar cell has the core structure of a thin film absorber (A) sandwiched between two wider band gap contact layers (CLs) that facilitate the separate collection of photogenerated electrons and holes from the absorber. CL through which impinging photons enter the absorber first is the window contact layer (WCL). The other $\mathrm{CL}$ is the back contact layer (BCL). The core photovoltaic element is abbreviated as WAB, after the initial letter of each layer of the core structure. In order to transport photogenerated electrons and holes to an external circuit, WCL is contacted with a transparent front electrode (TFE), and BCL is commonly contacted with a reflective back electrode (RBE), which also assists recapturing some of the low energy photons that passed through the absorber and BCL without getting absorbed.

A thin film WAB solar cell is deposited on a substrate. If the substrate is on the TFE side of the cell, then it has to be transparent so that the most of incoming photons can enter the cell. This thin film WAB cell configuration is referred to as the superstrate structure, Figure 1. If the substrate is on the RBE side, then it does not have to be transparent. This configuration is referred to as the substrate structure.

When intrinsic hydrogenated amorphous silicon $(a-S i: H)$ is used as the absorber, the resulting thin film WAB solar cell is here referred to as the $a-S i: H$ WAB solar cell, which is one of the leading commercial thin film solar cell technologies. For the conventional $a-S i$ : $H$ WAB solar cell, doped thin film silicon or its alloy (DTF-Si/A) is employed as CL. DTF-Si/A CL is typically processed by a chemical vapour deposition (CVD) method from expensive and dangerous gases that contain the dopant atoms [1][2]. These gasses are phosphine that is used for $n$-type doping, and diborane that is used for $p$-type doping of thin film silicon or its alloys. In order to prevent dopant contamination of the intrinsic $a-S i: H$ absorber, which is detrimental to the power conversion efficiency $(\eta)$ [3], a multi-chamber CVD system is employed for depositing thin film silicon based layers, which are WCL, A and BCL for the conventional $a-S i$ : $H$ WAB solar cell. The combination of these factors makes the manufacturing process of the conventional $a-S i$ : $H$ WB solar cell relatively expensive and complex [3].

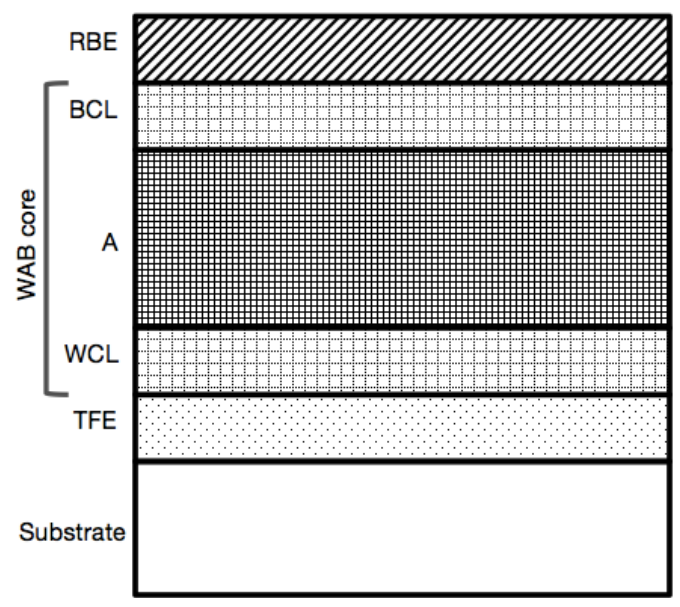

Figure 1. A schematic representation of a thin film WAB solar cell with the superstrate structure, deposited on a transparent substrate.

Because of the high density of tail states in their band gaps, DTF-Si/A CLs absorb a significant portion of the incoming photons [4]. However, the electrons and holes generated by photon absorption in DTF-Si/A CLs do not contribute to $\eta$ of the cell because of the high recombination rates in DTF-Si/A CLs, resulting primarily from doping [5]. Recombination is particularly problematic for the $p$-doped DTF-Si/A, which is typically employed as WCL in the superstrate structure [6]. In addition, the high recombination rates present in DTF-Si/A CLs decrease the probability of photogenerated electrons and holes passing through DTF-Si/A CLs towards their designated electrodes.

To circumnavigate the aforementioned disadvantages of using DTF-Si/A, CLs can be made from alternative materials that have higher transparency, and that are safer, simpler and cheaper to deposit. In this investigation, for the flexible, dopant free $a-S i: H$ WAB solar cell design with the superstrate structure, a layer of non-stoichiometric 
molybdenum oxide $\left(\mathrm{MoO}_{x}\right)$ [7]-[9] and a layer of lithium fluoride ( $L i F$ ) [7][8][10] are used as WCL and BCL respectively. Instead of the rigid and heavy quartz-based substrates used for the rigid, dopant free $a-S i$ : $H$ WAB solar cells investigated in our previous works [7][8], a flexible and lightweight transparent substrate is employed for the flexible cell investigated in this work.

\section{Solar Cell Structure And Processing}

The flexible, dopant free $a-S i: H$ WAB solar cell investigated here has the structure of $1 \mu \mathrm{m} \mathrm{ZnO}: \mathrm{Al}$ (TFE) | $10 \mathrm{~nm} \mathrm{MoO}_{x}$ (WCL) | $300 \mathrm{~nm}$ a-Si:H (A) | $1.5 \mathrm{~nm} \mathrm{LiF}$ (BCL) $\mid 300 \mathrm{~nm} \mathrm{Al}$ (RBE), deposited on a flexible and transparent ClearOhm ${ }^{\mathrm{TM}}$ (Cambrios) substrate, which is a flat polyethylene terephthalate film covered by a percolated network of silver nanowires. This substrate weighs less per surface area than the quartz-based substrates.

Prior to any deposition step, the ClearOhm ${ }^{\mathrm{TM}}$ substrate is rinsed by deionised water and dried with compressed nitrogen gas. The $Z n O: A l$ TFE is deposited on this substrate by the radio frequency magnetron sputtering method from a $\mathrm{ZnO}: \mathrm{Al}_{2} \mathrm{O}_{3}$ ceramic target. This is a physical vapour deposition (PVD) method. The TFE surface is textured by $\mathrm{HCl}$ etching. This step is significant in achieving high $\eta$, since the $a-S i: H \mathrm{WAB}$ solar cell with the optimally textured interfaces is able to generate considerably more short circuit current density $\left(J_{S C}\right)$ than the cell with smooth interfaces [11].

The intrinsic $a-S i: H$ absorber of the flexible cell is processed at $200^{\circ} \mathrm{C}$ by the plasma enhanced CVD method, which uses only one CVD deposition chamber. The $M_{0} O_{x}$ WCL, the $L i F \mathrm{BCL}$, and the $A l \mathrm{RBE}$ are all deposited by thermal evaporation at room temperature in the same single chamber PVD system from stoichiometric $\mathrm{MoO}_{3}$ powder, from $L i F$ powder, and from $A l$ pellets respectively.

The incomplete solar cell precursors are exposed to ambient air atmosphere between the depositions steps, except between the deposition steps of the $L i F \mathrm{BCL}$ and the $A l \mathrm{RBE}$, which are processed sequentially in the same thermal evaporation deposition run without breaking vacuum. A shadow mask used during BCL $\mid$ RBE deposition defines the planar size of the flexible cell, which is $4 \times 4 \mathrm{~mm}^{2}$.

After the TFE deposition step, the resulting solar cell precursor, i.e. the $\mathrm{ZnO}: \mathrm{Al}$ covered ClearOhm ${ }^{\mathrm{TM}}$ substrate, is found to have a prominent curvature. Therefore, in order to reduce the level of uneven film coverage during the subsequent deposition steps, solar cell precursors are clamped flat.

After completing the last deposition step, the flexible solar cells are annealed in a conventional oven in ambient air atmosphere for one hour at $120^{\circ} \mathrm{C}$, since the post-deposition annealing treatment at this temperature is found to improve $\eta$ of the $a-S i$ : $H$ WAB solar cell with the $M_{o} O_{x}$ WCL [9] and $\eta$ of the $a-S i: H \mathrm{WAB}$ solar cell with the $L i F$ BCL [10].

\section{Solar Cell Characterisation}

The current density and voltage (JV) characteristics of the solar cells are determined by using a PASAN AM1.5 solar simulator system with AM1.5 irradiance. The JV characterisation is employed for calculating the values of $J_{S C}$, of the open circuit voltage $\left(V_{O C}\right)$, of the series resistance $\left(R_{S}\right)$ and of the shunt resistance $\left(R_{S h t}\right)$.

The $J V$ measurements are carried out at room temperature. The cells are also clamped flat during these measurements.

\section{RESUlTS AND DISCUSSION}

Despite their curved shapes, the flexible and dopant free $a-S i: H \mathrm{WAB}$ solar cells are physically stable. There is no visible cracking, when they are flexed repetitively. The flexible cells also have good adherence to their substrate with no observed peeling.

The prominent curvature of the cell precursor observed after the ZnO:Al TFE deposition can be explained by the difference in the thermal expansion coefficients of the ClearOhm ${ }^{\mathrm{TM}}$ substrate and the $\mathrm{ZnO}: A l$ TFE. As TFE and the substrate cool following the $\mathrm{ZnO}: \mathrm{Al}$ deposition, they are likely to contract at significantly different rates. This would increase the stress at the interface between the $\mathrm{ZnO}: \mathrm{Al}$ TFE and the substrate [12], resulting in the associated cell precursor getting curved. The curvature developed after the $\mathrm{ZnO}: \mathrm{Al}$ deposition is observed to dominate the over-all curvature of the fully processed solar cells.

The increasing stress with increasing film curvature in the $\mathrm{ZnO}: \mathrm{Al}$ TFE is expected to be inversely correlated with the conductivity of TFE [13]. Therefore, the prominent curvature of the flexible solar cell would explain the high $R_{S}$ value of $36.6 \Omega \mathrm{cm} . R_{S}$ of a few ohms or more is known to degrade solar cell performance [2].

Alternate clamping and relaxing of the curved cell precursor during different deposition steps, and clamping of the curved solar cells during $J V$ characterisation are likely to increase the probability of pinhole formation. The $L i F$ BCL is especially susceptible to pinhole formation, as it is significantly thinner than the other layers. Pinholes cause leakage current, which is associated with low $R_{S h t}$ [14]. Hence, pinhole formation is the likely reason for the very low $R_{S h t}$ value of $225 \Omega . \mathrm{cm}^{2}$, which is within the range of the $R_{S h t}$ values that are found to degrade solar cell performance [2].

Since fill factor $(F F)$ is highly influenced by both $R_{S h t}$ and $R_{S}$ [2], their unfavourable values are considered to be the main reasons for the inferior $F F$ of the flexible, dopant free $a-S i: H$ WAB cell, compared to $F F$ of the rigid, dopant free $a-S i: H$ WAB cell with the same structure that is deposited on an Asahi U substrate in the same deposition systems under the same deposition conditions [15], Figure 2. Asahi U substrate used for this rigid cell is an Asahi type quartz that is coated with a textured, conductive and transparent layer of $\mathrm{SnO}_{2}: \mathrm{F}$ [16], which functions as TFE for the rigid cell. 


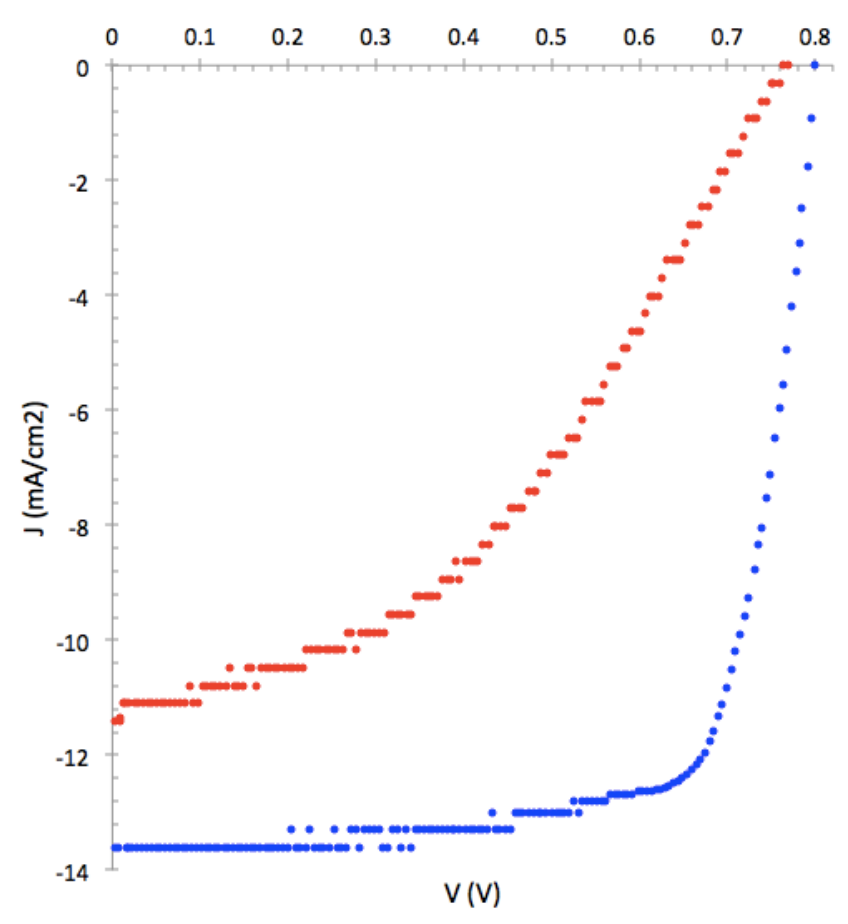

Figure 2. The $J V$ curves of the best performing flexible, dopant free $a-S i$ : $H \mathrm{WAB}$ cell (red), and of the rigid, dopant free $a-S i: H \mathrm{WAB}$ cell (blue) [15]. Both cells have identical layers expect their TFEs and substrates.

By optimising the $\mathrm{ZnO}: \mathrm{Al}$ deposition on the $\mathrm{ClearOhm}^{\mathrm{TM}}$ substrate, the $Z n O: A l$ film stress can be reduced [13], resulting in TFE that has better conductivity and reduced curvature. Therefore, it should be possible to improve the parasitic resistance values of $R_{S h t}$ and $R_{S}$, so that a better $F F$ can be achieved for the flexible cell.

The best performing flexible, dopant free $a-S i: H$ WAB cell has $V_{O C}$ of $0.764 \mathrm{~V}$ and $J_{S C}$ of $11.31 \mathrm{~mA} / \mathrm{cm}^{2}$. The low transparency of the annealed ClearOhm ${ }^{\mathrm{TM}}$ substrate is one of the main reasons for the relatively low $J_{S C}$, Figure 2. Furthermore, due to the imperfect mechanical clamping of the curved cells during $J V$ characterisation, the active cell area for impinging photons is noticeably smaller than $4 \times 4 \mathrm{~mm}^{2}$, which is used for $J_{S C}$ calculations. Consequently, the $J_{S C}$ value calculated from the $J V$ characterisation data underestimates the value of $J_{S C}$ for the flexible cells.

It is clear that $J_{S C}$ can be improved by using a flexible substrate that retains higher transparency than the ClearOhm ${ }^{\mathrm{TM}}$ film, after cell processing is completed. $J_{S C}$ can also be improved by using the substrate cell configuration, where the solar cell is deposited in reverse order on a flexible substrate, which does not need to be transparent. This configuration should increase the amount of photons reaching the absorber.

One of the main reasons for the relatively low $V_{O C}$ value of the $a-S i$ : $H \mathrm{WAB}$ solar cell with $\mathrm{MoO}_{x} \mathrm{WCL}$ is attributed to air exposure of the cell precursor between the deposition steps of $\mathrm{MoO}_{x} \mathrm{WCL}$ and the $a-\mathrm{Si}: \mathrm{H}$ absorber [9]. Thus, depositing the $\mathrm{MoO}_{x}$ and $a-S i: H$ layers sequentially without breaking vacuum is expected to improve the $V_{O C}$. In addition, $V_{O C}$ is known to increase with increasing $R_{S h t}$ [14]. Therefore, increasing the $R_{S h t}$ value is expected to further improve $V_{O C}$.

\section{CONCLUSION}

The proof of concept for the flexible, dopant free $a-S i: H$ WAB solar cell is demonstrated. The processing of this cell eliminates the use of dangerous dopant gases and the need for multi-chamber CVD reactor. Combination of these factors should make the $a-S i: H$ WAB solar cell manufacturing process safer, simpler and cheaper. Furthermore, the use of lightweight and flexible substrate increases the application range for the dopant free $a-S i$ : $H \mathrm{WAB}$ solar cells.

Since this is only a proof of concept device, the power conversion efficiency parameters of $V_{O C}, J_{S C}$, and $F F$ have the potential to be improved by deposition optimisation; especially regarding the $\mathrm{ZnO}: \mathrm{Al}$ and the $\mathrm{MoO}_{x}$ layers; and by employing alternative flexible and transparent substrates; or by employing flexible and opaque substrates in the substrate solar cell configuration.

Note that $\mathrm{MoO}_{x}$ can be replaced by other dopant free materials that have the suitable properties to be used as WCL, such as $V_{2} \mathrm{O}_{x}$ [17], PEDOT: $P S S$ and $\mathrm{Cu}_{2} \mathrm{O}_{x}$ [7]. Similalry, $L i F$ can be replaced by other dopant free materials that have the suitable properties to be used as BCL, such as $M g O$ [15].

Also note that the flexible, light-weight, and dopant free thin film WAB solar cell concept demonstrated here can be applied to the other thin film solar cells, including multiple junction thin film silicon solar cells, such as the micromorph solar cell.

We thank Prof Miro Zeman of Delft University of Technology, Delft, Netherlands for giving us access to his laboratory for this work.

\section{REFERENCES}

[1] V. M. Fthenakis, P. D. Moskowitz, "Characterization and control of phosphine hazards in photovoltaic cell manufacture," Solar Cells, vol. 22, pp. 303-317, 1987.

[2] T. Markvart, L. Castafier, Practical Handbook of Photovoltaics: Fundamentals and Applications. Oxford, UK: Elsevier, 2003.

[3] A. Shah, J. Meier, A. Buechel, U. Kroll, J. Steinhauser, F. Meillaud, H. Schade, D. Domine, "Towards very low-cost mass production of thin-film silicon photovoltaic (PV) solar modules on glass," Thin Solid Films, vol. 502, pp. 292-299, 2006.

[4] J. Poortmans, V. Arkhipov, Thin Film Solar Cells: Fabrication, Characterization and Applications. Chichester, UK: John Wiley \& Sons, 2006.

[5] R. A. Street, Hydrogenated Amorphous Silicon. Cambridge, UK: Cambridge University Press, 1991.

[6] H. Okamoto, Y. Nitta, T. Yamaguchi, Y. Hamakawa, "Device physics and design of a-Si ITO / p-i-n heteroface solar cells," Solar Energy Materials, vol. 2, pp. 313-325, 1980. 
[7] E. Ore, G. Amaratunga, "Thin heterojunction a-Si:H photovoltaic cell design with no doped a-Si:H layers". In 40th IEEE Photovoltaic Specialist Conference (PVSC), 2014, pp. 3087-3089.

[8] E. Ore, G. Amaratunga, "Cylindrical ultra-thin a-Si:H photovoltaic cell with no doped layers," MRS Advances, vol. 2, issue 15, pp. 825-833, 2017.

[9] E. Ore, J. Melskens, A. Smets, M. Zeman, G. Amaratunga, "MoOx hole collection layer for a-Si:H based photovoltaic cells," MRS Advances, vol. 1, issue 14, pp. 977-983, 2016.

[10] E. Ore, J. Melskens, A. Smets, M. Zeman, G. Amaratunga, "Ultra-thin $\mathrm{LiF}$ layer as the electron collector for a-Si:H based photovoltaic cell," MRS Advances, vol. 2, issue 15, pp. 863-867, 2017.

[11] A. Čampa, O. Isabella, R. van Erven, P. Peeters, H. Borg, J. Krč, M. Topič, M. Zeman, "Optimal design of periodic surface texture for thin-film a-Si:H solar cells," Progress in Photovoltaics: Research and Applications, vol. 18, pp. 160-167, 2010.

[12] A. Bishop, Vacuum Deposition Onto Webs, Films, And Foils. Norwich, New York, USA: William Andrew Publishing, 2007.
[13] J. S. Fernandez, F. B. Naranjo, "Optimization of aluminumdoped zinc oxide films deposited at low temperature by radiofrequency sputtering on flexible substrates for solar cell applications," Solar Energy Materials \& Solar Cells, vol. 94 pp. 157-163, 2010.

[14] R. D. Rugescu, Solar Energy. Olajnica, Vukovar, Croatia: Intech, 2010.

[15] This work is carried out by the authors of this paper and it is not published yet.

[16] K. Sato, Y. Gotoh, Y. Wakayama, Y. Hayashi, K. Adachi, H. Nishimura, "Highly textured $\mathrm{SnO} 2: \mathrm{F}$ TCO films for a-Si solar cells", Rep. Res. Lab. Asahi Glass Co. Ltd, vol. 42, pp. 129-137, 1992.

[17] E. Ore, G. Amaratunga, S. De Wolf, "HIT solar cell with V2Ox window layer," MRS Advances, vol. 2, issue 53, pp. 3147-3156, 2017. 